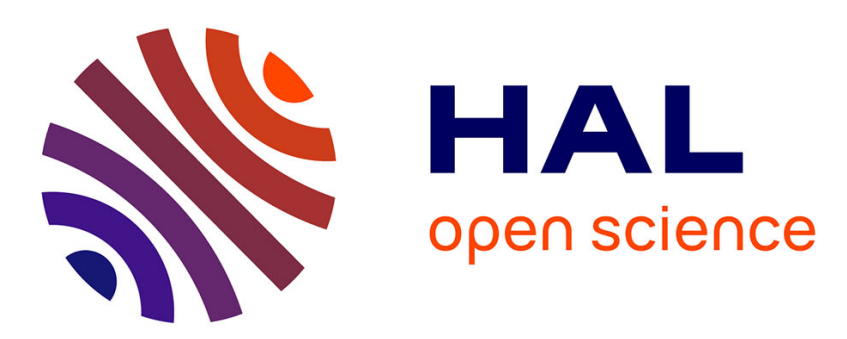

\title{
Flood regimes - recent development and future under climate change
}

\author{
Eric Sauquet, M. Lang
}

\section{To cite this version:}

Eric Sauquet, M. Lang. Flood regimes - recent development and future under climate change. Vinet, F. (ed). Floods, Volume 1 - Risk Knowledge, ISTE Press - Elsevier, pp.299-309, 2017. hal-01741600

\author{
HAL Id: hal-01741600 \\ https://hal.science/hal-01741600
}

Submitted on 23 Mar 2018

HAL is a multi-disciplinary open access archive for the deposit and dissemination of scientific research documents, whether they are published or not. The documents may come from teaching and research institutions in France or abroad, or from public or private research centers.
L'archive ouverte pluridisciplinaire HAL, est destinée au dépôt et à la diffusion de documents scientifiques de niveau recherche, publiés ou non, émanant des établissements d'enseignement et de recherche français ou étrangers, des laboratoires publics ou privés. 


\title{
Flood regimes - recent development and future under climate change
}

\author{
Eric SAUQUET, Michel LANG \\ Irstea, UR HHLY, 5 rue de la Doua BP32108, 69616 Villeurbanne, France
}

When a major new flood event occurs, many people wonder about the link between the extreme event observed and the global phenomenon of climate change, especially as damage caused by floods has increased significantly in the last few decades. The temptation is to interpret them as warning signs of the effects of climate disruption. We might also fear more severe and frequent extreme events in the next few years, relating to either high or low flows, calling into question flood control measures and the rules for sharing water resources.

When analyzing the effect of climate change on the river flow regime hydrologists usually carry out two complementary approaches. The first, focused on the study of recent observations, is based on statistical analyses to detect non-stationarities in long flow time series. The second involves forcing a modeling chain by global scenarios of the evolution of the concentration of greenhouse gases in the atmosphere: it enables future flow time series to be simulated. The dual perspective - past and future provides objective information on the characterization of significant changes, reveals elements of causality (natural and/or anthropogenic) and enables the consistency of the simulations produced by models with the most recent observations to be assessed.

This chapter summarizes recent research into these two aspects on French territory, along with a few general methodological points. 


\subsection{Observing a recent evolution in the flood regime?}

\subsubsection{Methodological aspects}

The river flow pattern is intrinsically variable in time, with flows determined each year by meteorological forcings and the water status of drainage basins. The study of extreme values is usually based on a sample composed of the maximum flow values measured each year. Assuming moderate changes, we might predict a gradual shift in annual maximum values, producing a new range of possible values, but partly overlapping with the former. Statistical tests provide a degree of objective proof of a temporal evolution in the samples, for example, of instantaneous annual maximum flows or any other characteristic (number of days with a flow exceeding a high threshold value, etc.).

These tests examine the likelihood of a hypothesis given a sample of values $x_{i}$, $i=1 . ., N$. The testing process leads to the choice between the stationarity hypothesis $H_{0}$ (absence of change) and its alternative $H_{l}$, given that only one is true. Despite everything, there is still room for errors: refusing $H_{0}$ while $H_{0}$ is true (risk of $1^{\text {st }}$ kind) or accepting $H_{0}$ while $H_{1}$ is true (risk of $2^{\text {nd }}$ kind). The tests are all based on a decision variable $Z$, whose distribution is known under the hypothesis $H_{0}$. We can therefore define the bounds of an interval that brings together $(1-\alpha) \%$ of the values that the statistics can take if $H_{0}$ is true and locate the $z$ value taken for the analyzed sample. If $z$ is located outside the interval, the value is deemed implausible and the hypothesis $H_{0}$ is rejected, with an error risk $\alpha$ defined in advance by the user (generally $\alpha<10 \%$ ). The lower $\alpha$, the more extensive the interval; $H_{0}$ is therefore rejected only in extremely rare cases. There are many tests:

- $\quad$ those suited to detecting a rupture in a time series (e.g. [PET 79, BUI 82]);

- $\quad$ those suited to identifying trends (e.g. Spearman [LEH 75]; Mann-Kendall [MAN 45, KEN 75]).

They differ in the underlying hypotheses on the sample $x_{i}, i=1 . ., N$, and in their relative performance according to the number of $N$ values, etc. Other regional tests can be applied, notably to measure the consistency of changes (i.e. sign of the trend or rupture date comparable between sites) within a set of gauging stations and ultimately draw more reliable conclusions.

A minimum of 30 years is recommended in order to break away from the decadal climate variability, i.e. to integrate a sample representative of the alternation of dry and humid years. There is a real difficulty when it comes to accessing long time series: river flow monitoring is recent, even in developed countries. Even if records are available, they often concern catchments with major socio-economic stakes, which have undergone modifications of the natural river flow regime and are 
equipped for watercourse management needs. An anthropogenic signal should be filtered before a conclusion is drawn as to a possible drift due to climate change.

\subsubsection{Summary of stationarity studies}

Stationarity studies mainly involve analyzing stationarity of peak discharges; it is, in fact, the flood peak that generally qualifies the severity of the event. The sample used is usually composed of the annual maximum discharges or maxima of episodes exceeding a flow threshold, instantaneous or daily.

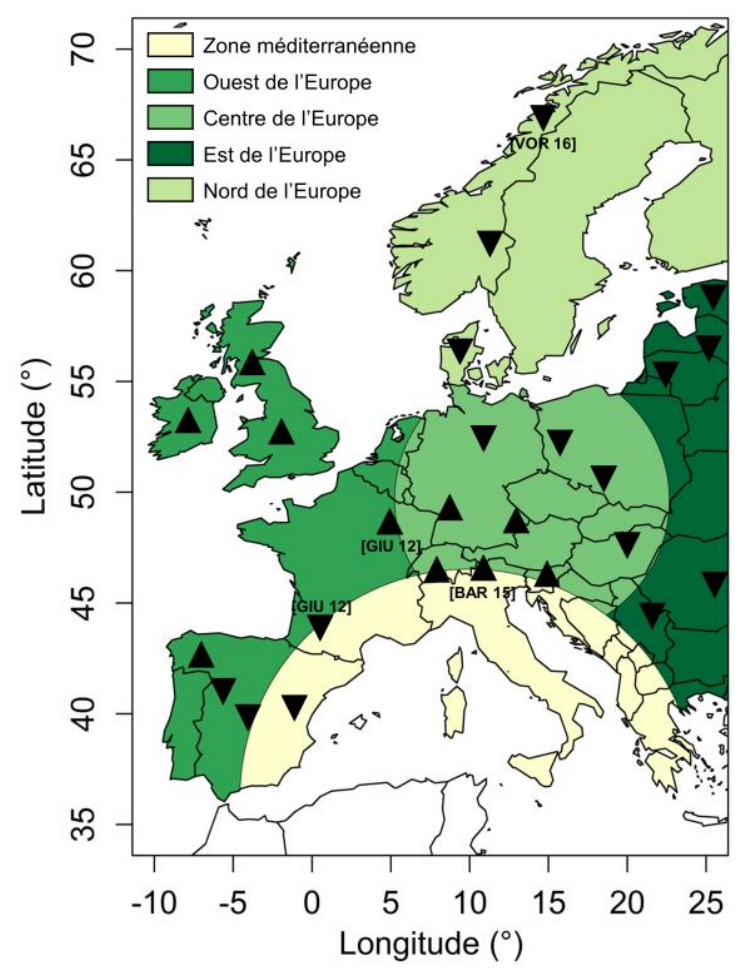

Figure 18.1. Overview of the main trends detected in Europe. The direction of the arrows indicates the dominant trend, including for regions with non-significant changes (according to [HAL 14], updated in 2016, identification of references cited here) 
A summary of studies into climatic and hydrological extremes on land surfaces is provided in the IPCC reports [IPC 07, IPC 12]) and the conclusions of the last report [IPC 13] are in line with previous ones: to this day, there is no consensus on observed trends in floods, which may be shared on the global scale, whether in terms of frequency or severity of events. This conclusion at the global scale is also true on a smaller scale, that of Europe [HAL 14, MAD 14], which presents trends of both increase (in central Europe and the British Isles) and decrease (on the Iberian Peninsula and in Eastern Europe) in flood hazard, due to the process behind the differentiated high waters (Figure 19.1).

The most complete and recent stationarity analysis in France was carried by [GIU 12] on a set of 209 gauging stations with at least 40 years of daily flows, with measurements deemed to be of high quality and no notable influence on high flows. Exchanges with data providers have made it possible to eliminate sets marred by metrological errors. The 209 stations can be clustered as follows: 174 with rainfallcaused floods, 7 with snowmelt-caused floods and 28 with a mixed flood generation mechanisms. Taking into account the overlap of data, the results obtained are representative of the period 1968-2008. The annual maximum flows were transformed into standard centered variables reduced to enable inter-site comparisons; the trends detected at the stations indicated in Figure 19.1 are calculated from these transformed variables.

Various tests have been considered, with the aim of examining the stationarity at the gauging stations, the regional significance (identifying whether the changes observed at the stations are likely to be due to mere chance) and the consistency of changes at the regional scale. They have been applied to two variables related to the flood magnitude: the annual maximum daily flow $Q J X A$ and the total volume generated $H E$ during high waters for flows above a fixed high threshold $S$, and to two variables related to the flood seasonality: the day of the year corresponding to QJXA and the day of the year corresponding to the center of mass at $50 \%$ of the annual volume $H F$ (date on which $50 \%$ of $H E$ has flowed on the days exceeding the threshold $S$ ). Figure 19.2 illustrates the results obtained for the daily peak flow QJXA. The map shows a north-south contrast (with an increase in the north part and a decrease in the south part). However, only a limited number of stations show significant changes and, ultimately, consistent and significant regional trends emerge only in the north-east of France, in the Massif Central and in the south-west (Landes and foothills of the Pyrenees). Similar results are obtained for the $H E$ variable; however, no northern region has a significant trend. In the majority of cases, it seems that the flood magnitude has decreased gradually over the period 1968-2008 in the south of France, while the north has not been affected by the changes. In terms of timing, only Brittany presents significant trends for earlier floods. 


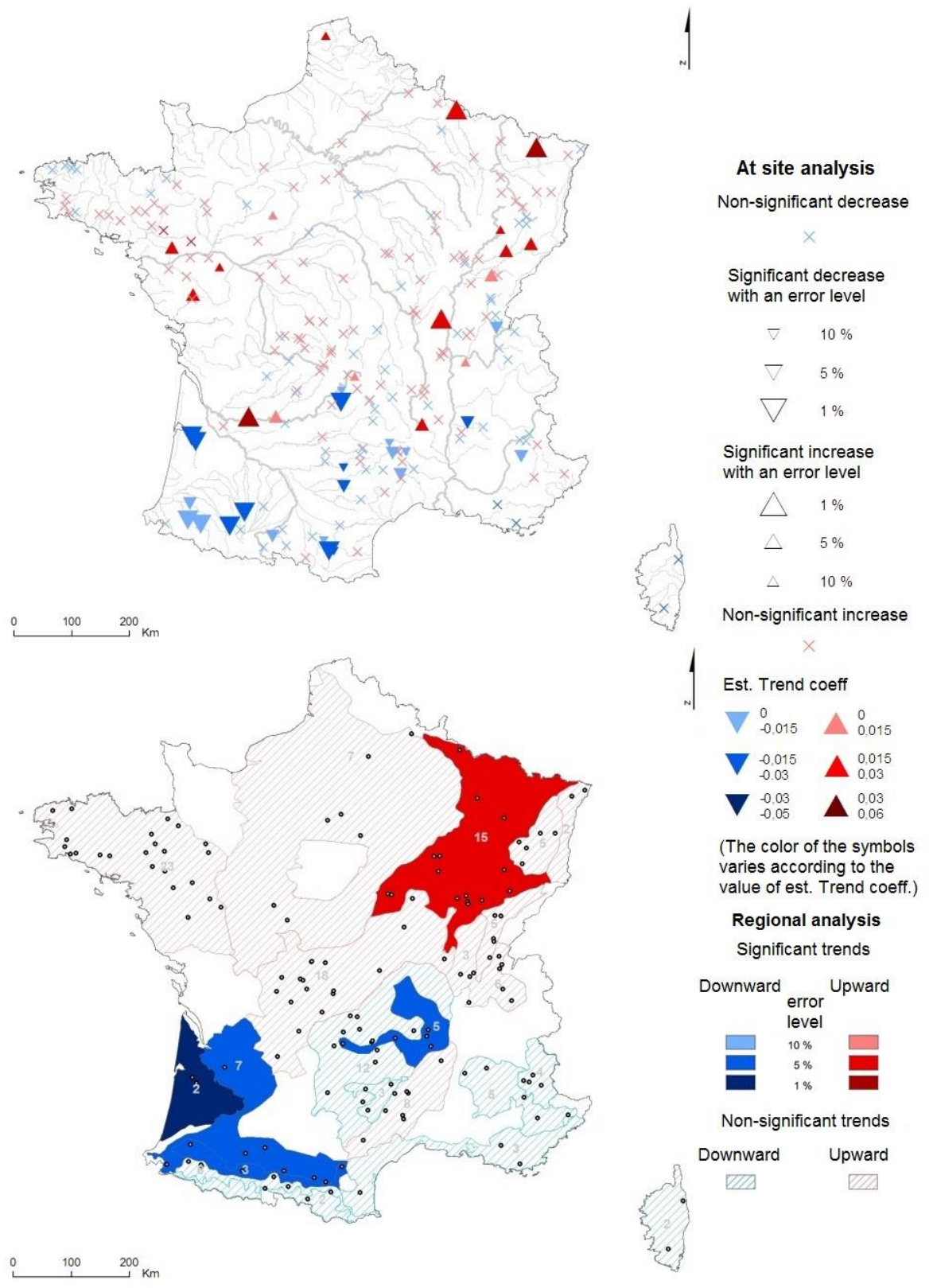

Figure 18.2. Trends in annual maximum daily flow, identified by statistical tests on gauging stations and on the regional scale (according to [GIU 12]). 
An international study focused on the Alps [BAR 15] examines the flood hazards in mountainous areas. The analyses covered 140 discharge time series, distributed across Germany, Austria, France, Italy, Slovenia and Switzerland. The results obtained, representing the period 1961-2005, show the absence of change in flood risks at the global scale; however, there is clearly a trend for increase in the maximas and volumes of snowmelt flows for glacial regimes, and a consistent shift toward an earlier start of snowmelt flow is detected. The changes observed are consistent with the effects expected of an increase in air temperature on glaciers and with the trends identified recently in Norway on the earlier occurrence of the melting season [VOR $16]$.

The fact that no generalized trend appears on the flood regime is related to the complexity of the physical processes that cause runoff. They depend both on climatic evolutions acting on different regional scales, but also, in an area with a lot of human involvement, on human activity - often flood control and land use change - which can be added to climate changes. Furthermore, the variability in discharge time series is generally very large, especially in the extreme domain, hence making it difficult to detect trends.

Ultimately, when a significant change is detected, one or more causes of these evolutions must be sought, a phase called "attribution" [MER 12], to determine how much is due to the climate and how much to land use planning in the catchment (e.g. hydraulic structures). [MAD 14] summarizes a dozen studies on attribution in Europe, which connect the changes observed to the flood regime to the increase in temperature, a change in atmospheric circulation patterns or the development of structures on river network.

\subsection{Impact studies for anticipating future risks}

\subsubsection{Methodological aspects}

Impact studies aim to characterize a system subject to various disturbances as fully as possible (diagnosis, sensitivity and environmental response). In the context of climate change, the approach is based on chains of models reproducing the past and likely to describe the future, with an input of the climate representation. Outputs are discharge time series from which hydrological variable(s) of interest are derived, characterizing the future of the system studied.

The climatic models (GCM, General Circulation Model) provide projections for the $21^{\text {st }}$ century, but at a too coarse resolution to make them usable to describe climate at the local scale. A method called "downscaling" is required to access the 
relevant spatial and temporal scales and simultaneously correct the bias of the GCMs.

Impact studies differ in the hypotheses and approaches considered, from the choice of greenhouse gas emission scenario to the hydrological models applied, due to a wide range of methods and existing models. They are all constantly evolving and improving, taking into account climate change issues. They differ in their foundations (statistical or physical representation), the main processes represented, the way of integrating the spatial heterogeneity of the study area, etc. No model can claim to be perfect or universal, and the choice between several hypotheses cannot always be distinct.

In the face of this diversity, a multi-model approach through the analysis of the range of the outputs is the most convenient method to assess the uncertainties: a set of GCM outputs in different greenhouse gas emission scenarios, regionalized according to various downscaling methods, supply a panel of hydrological models. Only few studies have examined all aspects relating to uncertainties (notably due to costly and time-consuming calculations); most of them explore one aspect. Without a shared methodological foundation, comparison between the conclusions of studies is often difficult.

\subsubsection{Summary of impact studies}

The hypothesis is often made that a warmer climate may lead to an intensification of the global water cycle, with an increase in the evaporation of open water surfaces, atmospheric humidity, precipitation and extremes, all leading to more severe floods.

The results of impact studies are far from supportive of this assumption.

[ROJ 11] and [HIR 13] suggest an increase in the flood severity for a large number of catchments, particularly in the west of Europe at the end of the $21^{\text {st }}$ century in A2 and RCP8.5 greenhouse gas emission scenarios, the most extreme and the most pessimistic. Finally, [ROU 16] propose a contrasting vision of hydrology in a climate increased by $+2^{\circ} \mathrm{C}$. Areas located to the north of the $60^{\circ} \mathrm{N}$ latitude experience a decrease in 10 year $(Q J X A 10)$ and 100 year $(Q J X A 100)$ return period flood quantiles, while those in the south see them increase (including France).

Examination of the conclusions of national impact studies carried out in France produces less clear results. 


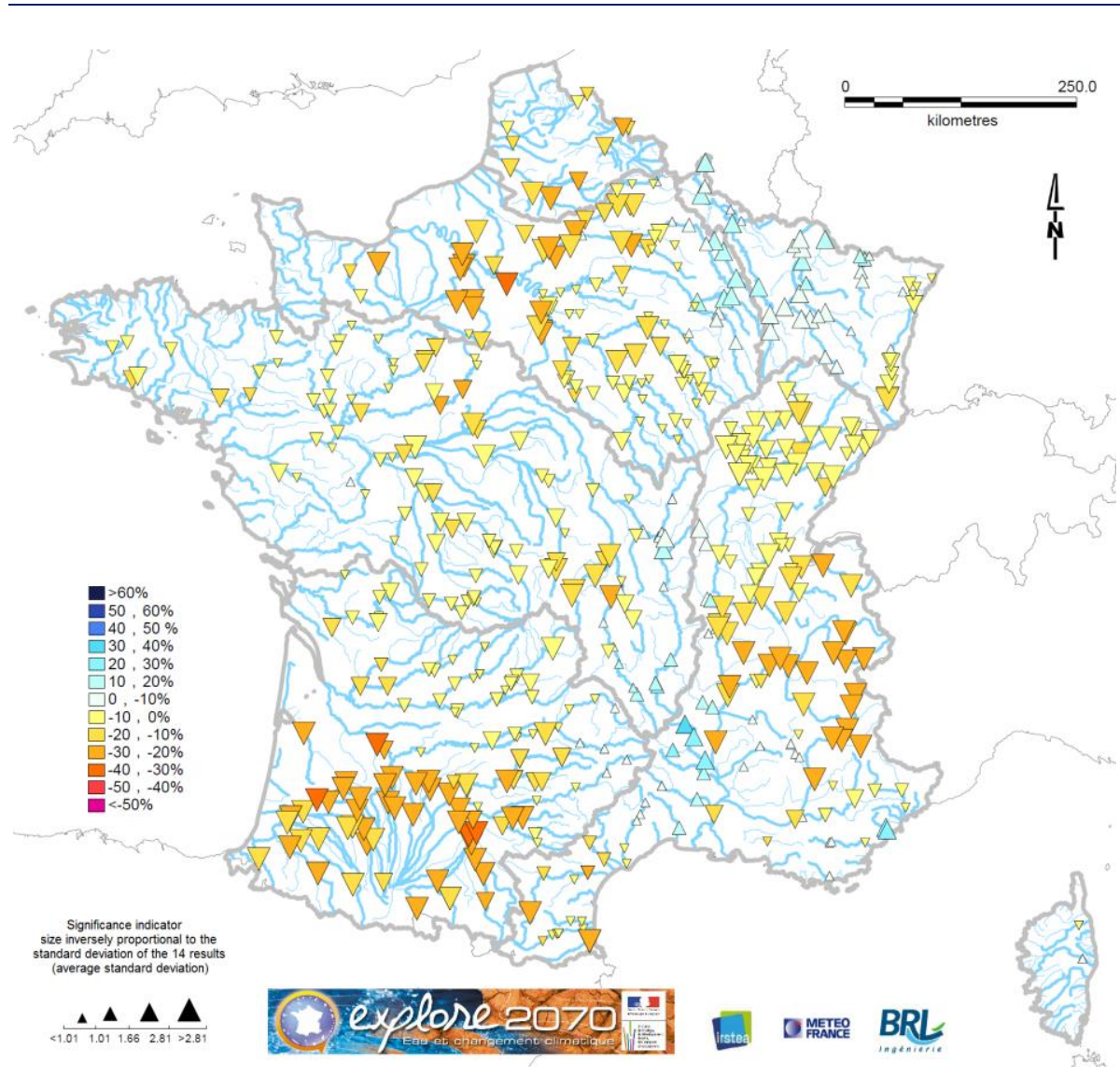

Figure 18.3. Possible relative evolutions (in \%) of the 10 year return period flood quantile (QJXA10) between 1961-1990 and 2046-2065, in the A1B scenarioAverage multi-models of changes established on 14 simulations. The colour of the dots represents the intensity of the change and their size relates to the convergence of the simulations.

The RexHySS project [DUC 11] revealed the absence of a significant and consistent evolution in the flood regime in the Seine River basin during the $21^{\text {st }}$ century, the changes simulated on the high flood quantile QJXA10 and over the flood duration being moderate. The 100-year return period flood in Paris at the end of the century would be around the same as today. On the national scale, according to the results of the Explore2070 prospective study [CHA 13], (Figure 19.3) a generalized decrease of the QJXA10 quantile is projected on the 2046-2065 horizon in the A1B scenario in mountain areas (Alps, Pyrenees, Jura), on the left-bank tributaries of the Garonne and in the two western thirds of the Seine-Normandy basin. It seems that the QJXA10 quantile could increase in the Cévennes and in north-east France. It should be noted that it is very difficult for hydrological models 
to reproduce the current regime in mountainous catchments, which can affect the projected decreases. Recently, [DAY 15] has shown that the set of projections obtained in four RCP scenarios do not lead to notable change in flood hazards on the 2070-2100 horizon, with the exception of north-east France for the RCP8.5 scenarios, due to the increase in precipitation. The conclusions of work carried out in France contradict the results obtained on a European scale, which were higher.

\subsection{Conclusions}

Studies focusing on past and future evolutions of hydrological regimes in France show that climate change has not left its mark on floods (few significant evolutions observed) and that the evolution of floods is uncertain, much more so than that of low flows: summer low flows ought to be more severe on plains (due to increased evaporation and transpiration), while winter low flows ought to be more moderate in the mountains (due to greater liquid precipitation).

A wide range of hydrological projections can be perceived. Fundamentally, at our latitudes, GCMs are the main source of uncertainty in the future of high waters, as heavy rainfall is the main explanatory variable of floods. The simulated changes are not of the same intensity or sign (increase or decrease). The spread observed reflects the absence of consensus on the future of extreme precipitations in climatic projections, which seems to be partly filtered by hydrological models. Uncertainty, in terms of both the sign and intensity of the change, certainly makes it difficult to use simulation results to prepare for the future.

In practical terms, what should we do to anticipate the flood risks of the next few years? Alongside the work of the scientific community, we need to come up with methodological frameworks and suitable technical recommendations integrating uncertainties into decision-making. Some European nations (Norway, Germany, Belgium, Great Britain) have taken measures to size flood defense structures; this involves corrective factors applied to current values, modified according to the geographical sector in question [MAD 2014]. Large-scale flood risk studies are beginning to be carried out: they cross-reference the hazard with the exposure of populations [HIR 13]; they are still only summaries, but will be developed to be as close as possible to questions of planning.

Which avenues of research should be followed to better understand the future of flood regimes? We must, of course, continue to develop simulation tools, using improved knowledge of the physical mechanisms involved in the water cycle. "Bottom-up" approaches, alternatives to the more usual "top-down" approaches, which have been presented here, are starting to be used [PRU 10]. They bring back into question the notions of the vulnerability and sensitivity of systems subjected to 
external disruptions, and examine the likelihood of changes through climatic projections. Furthermore, it may be useful to return to major past flooding events in order to deepen our knowledge of extremes due to climatology and understand the possible consequences of such disasters in an evolutionary context, whether from a climatic point of view or in terms of land use and exposure to risk.

\subsection{References}

[BAR 15] BARD A., RENARD B., LANG M. et al., "Trends in the hydrologic regime of Alpine rivers”, Journal of Hydrology, vol. 529, p. 1823-1837, 2015.

[BUI 82] BuISHAND, T.A., "Some methods for testing the homogeneity of rainfall records", Journal of Hydrology, vol. 58, p. 11-27, 1982.

[CHA 13] Chauveau M., Chazot S., Perrin C et al., "Quels impacts des changements climatiques sur les eaux de surface en France à l'horizon 2070 ?”, La Houille Blanche, n 4, p. 5-15, 2013.

[DAY 15] DAYON G., Evolution du cycle hydrologique continental en France au cours des prochaines décennies, Mémoire de thèse, Université Toulouse 3 Paul Sabatier, Toulouse, 2015.

[DUC 11] Ducharne A., Sauquet E., Habets F. et al., "Evolution potentielle du régime des crues de la Seine sous changement climatique" La Houille Blanche, n¹, p. 51-57, doi:10.1051/lhb:2011006, 2011.

[GIU 12] Giuntoli I., Renard B., Lang M., Floods in France, dans KundZewicz, Z.W. (ED.), Changes in Flood Risk in Europe, p. 199-211, IAHS Special Publication 10, 2012.

[HAL 14] Hall J., ARheimer B., Borga M. et al., "Understanding flood regime changes in Europe: a state-of-the-art assessment”, Hydrology and Earth System Sciences, vol. 18, p. 2735-2772, doi:10.5194/hess-18-2735-2014, 2014.

[HIR 13] Hirabayashi Y., Mahendran R., Koirala S. et al., "Global flood risk under climate change", Nature Climate Change, vol. 3, p. 816-821, doi:10.1038/nclimate1911, 2013.

[IPC 07] IPCC, Climate Change 2007: Impacts, Adaptation and Vulnerability. Contribution of Working Group II to the Fourth Assessment Report of the Intergovernmental Panel on Climate Change [M.L. PARRY, O.F. CANZIANI, J.P. PALUTIKoF, P.J. VAN DER LiNDEN AND C.E. Hanson (EDS)], Cambridge University Press, Cambridge, UK, 2007.

[IPC 12] IPCC, Managing the Risks of Extreme Events and Disasters to Advance Climate Change Adaptation. A Special Report of Working Groups I and II of the Intergovernmental Panel on Climate Change [FIELD, C.B., V. BARRos, T.F. STOCKER, D. Qin, D.J. Dokken, K.L. Ebi, M.D. Mastrandrea, K.J. Mach, G.-K. Plattner, S.K. Allen, M. Tignor, AND P.M. Midgley (EDS.)], Cambridge University Press, Cambridge, UK, and New York, NY, USA, 2012. 
[IPC 13] IPCC, Climate Change 2013: The Physical Science Basis. Contribution of Working Group I to the Fifth Assessment Report of the Intergovernmental Panel on Climate Change" [STOCKer T.F., QIn D., PlatTNER G.-K. et al. (EDS.)], Cambridge University Press, Cambridge, United Kingdom and New York, NY, USA, 2013.

[KEN 75] Kendall M.G., Rank Correlation Methods, 4th edition, Charles Griffin, London, 1975.

[LEH 75] Lehmann E. L., Nonparametrics: Statistical Methods Based on Ranks, San Francisco. Holden-Day, Inc., 1975.

[MAD 14] Madsen H., LAwREnCE D., LANG M. et al., "Review of trend analysis and climate change projections of extreme precipitation and floods in Europe", Journal of Hydrology, vol. 519, p. 3634-3650, 2014.

[MAN 45] MANN H.B., "Non-parametric tests against trend", Econometrica , vol. 13, p. 163$171,1945$.

[MER 12] Merz B., Kundzewicz Z. W., Delgado J., HundecGa Y., Kreibich H., "Detection and attribution of changes in flood hazard and risk", dans KunDZEwICZ, Z.W. (ED.), Changes in Flood Risk in Europe, p. 435-458, IAHS Special Publication 10, 2012.

[PET 79] PetTitT A.N., “A Non-parametric Approach to the Change-point Problem”. Applied Statistics, vol. 28, n², p. 126-135, 1979.

[PRU 10] Prudhomme C., Wilby R.L., Crooks S. et al., "Scenario neutral approach to climate change impact studies: application to flood risk", Journal of Hydrology, vol. 390, $\mathrm{n}^{\circ} 3-4$, p. 198-209, 2010.

[ROJ 11] Rojas R., FeYen L., Dosio A. et al., "Improving pan-European hydrological simulation of extreme events through statistical bias correction of RCM-driven climate simulations", Hydrology and Earth System Sciences, 15, 2599-2620, 2011, doi:10.5194/hess-15-2599-2011.

[ROU 16] Roudier P., ANDersson J. C. M., Donnelly C. et al., "Projections of future floods and hydrological droughts in Europe under a $+2{ }^{\circ} \mathrm{C}$ global warming", Climatic Change, vol. 135, p. 341-355, doi:10.1007/s10584-015-1570-4, 2016.

[VOR 16] Vormoor K., LAWrence D., Schlichting L. et al., "Evidence for changes in the magnitude and frequency of observed rainfall vs. snowmelt driven floods in Norway Journal of Hydrology, vol. 538, p. 33-48, 2016. 